\section{Psicologia Escolar \\ e Educacional}

ARTIGO

DOI: http://dx.doi.org/10.1590/2175-35392021224756

Localizador - e224756

\title{
UM RELATO DA EDUCAÇÃO DE ESTUDANTES SURDOS NO MUNICÍPIO DE CHAPECÓ (SC)
}

\author{
Tania Mara Zancanaro Pieczkowski ${ }^{1} \mathbb{D}$
}

\begin{abstract}
RESUMO
Este artigo objetiva evidenciar a educação de surdos no município de Chapecó (SC), explicitando os fundamentos teóricos estruturantes e os processos de formação docente para esta especificidade no período de 1996 a 2016. A pergunta que orientou a investigação assim se constitui: Como a educação de surdos foi desenvolvida de 1996 a 2016 na rede municipal de educação de Chapecó e quais os fundamentos teóricos estruturantes nos processos de formação docente? A pesquisa se caracteriza como qualitativa numa perspectiva pós-estruturalista. Participaram do estudo três secretários municipais de educação que exerceram a função por maior tempo em cada gestão municipal do período pesquisado. Além de pesquisa documental, foram realizadas entrevistas semiestruturadas, gravadas, transcritas e organizadas em agrupamentos temáticos. As materialidades empíricas foram examinadas por meio da análise do discurso com referenciais foucaultianos. O estudo evidencia que em cada tempo são instituídas verdades acerca da educação de surdos e que abordagens teórico-metodológicas, adotadas em contextos históricos e geográficos mais amplos, se manifestam também na região investigada.
\end{abstract}

Palavras-chave: Educação especial; educação de surdos; educação inclusiva

\section{A report about the education of deaf students in the city of Chapecó (SC)}

\begin{abstract}
This article aims to highlight the education of the deaf in the city of Chapecó (SC), explaining the structural theoretical foundations and the processes of teacher education for this specificity in the period 1996 to 2016 . The question that guided the investigation is: How was the education for the deaf developed from 1996 to 2016 in the municipal education network of Chapecó and what are the structuring theoretical foundations in teacher training processes? The research is characterized as qualitative in a post-structuralist perspective. Three municipal education secretaries participated in the study, who exercised the function for the longest time in each municipal administration during the researched period. In addition to documentary research, semi-structured interviews were conducted, recorded, transcribed and organized into thematic groups. The empirical materialities were examined through discourse analysis with Foucaultian references. The study shows that truths about deaf education are established at each time and that theoretical-methodological approaches, adopted in broader historical and geographical contexts, are also manifested in the investigated region.
\end{abstract}

Keywords: Special education; deaf education; inclusive education

\section{Un relato de la educación de estudiantes sordos en el municipio de Chapecó (SC)}

\section{RESUMEN}

En este artículo se tiene como objetivo evidenciar la educación de sordos en el municipio de Chapecó (SC), explicitando los fundamentos teóricos estructurantes y los procesos de formación docente para esta especificidad en el período de 1996 a 2016. La pregunta que orientó la investigación fue: ¿Cómo la educación de sordos fue desarrollada de 1996 a 2016 en la red municipal de educación de Chapecó y cuáles son los fundamentos teóricos estructurantes en los procesos de formación docente? La investigación se caracteriza como cualitativa en una perspectiva posestructuralista. Participaron del estudio tres secretarios municipales de educación que ejercieron la función por más tiempo en cada gestión municipal del período investigado. Además de investigación documental, se realizaron entrevistas semiestructuradas, gravadas, transcriptas y organizadas en grupos temáticos. Las materialidades empíricas se examinaron por intermedio del análisis del discurso con referenciales foucaultianos. El estudio evidencia que en cada tiempo son instituidas verdades acerca de la educación de sordos y que abordajes teórico-metodológicas, adoptadas en contextos históricos y geográficos más amplios, se manifiestan también en la región investigada.

Palabras clave: Educación especial; educación para sordos; educación inclusiva

\footnotetext{
${ }^{1}$ Universidade Comunitária da Região de Chapecó - Chapecó - Santa Catarina - SC - Brasil; taniazp@unochapeco.edu.br
} 


\section{INTRODUÇÃO}

Este artigo objetiva evidenciar a educação de surdos no município de Chapecó (SC) e os fundamentos teóricos estruturantes para os processos de formação docente para a atuação com o público especificado, no período de 1996 a 2016. Este texto é um excerto de um projeto de pesquisa mais amplo, desenvolvido por professores vinculados a um Programa de Pós-Graduação em Educação de uma universidade localizada no oeste de Santa Catarina. O objetivo geral da investigação, na sua amplitude, foi identificar e compreender os desafios políticos e epistemológicos presentes no processo de formação continuada de professores da Educação Básica, implementado pela Rede Municipal de Ensino de Chapecó (SC), do período de 1996 (ano de aprovação da Lei de Diretrizes e Bases para a Educação Nacional - LDB) a 2016 (ano em que o projeto de pesquisa foi aprovado) quanto as suas diretrizes de formação e suas dimensões epistêmico-pedagógicas.

Na educação/escolarização de surdos em diferentes contextos mundiais, três abordagens teórico metodológicas foram predominantes: a oralista, a comunicação total e o bilinguismo. Em cada tempo, algumas verdades acerca da educação de surdos foram predominantes. Segundo Lopes, a educação de surdos ocupou a atenção de experts de diferentes áreas do saber, amparados especialmente em discursos clínicos. A maioria desses discursos produziu classificações e saberes que influenciaram a sociedade a conceber os surdos como sujeitos a serem "[...] 'tratados', 'corrigidos' e 'normalizados' através de terapias, treinamentos orofaciais, protetização, implantes cocleares e outras tecnologias avançadas que buscam, pela ciborguização do corpo, a condição de normalidade." (Lopes, 2011, p. 9).

O estudo evidenciou que foi na configuração clínica que, na passagem da década de 1970 para a década de 1980, teve início a educação de surdos no município pesquisado. Nesse período, a preocupação era com a oralização dos surdos, e equipamentos como espelhos, microfones, instrumentos de sopro e sucção faziam parte dos recursos utilizados pelos professores, em parceria com fonoaudiólogos, que atuavam no mesmo espaço. Tempos depois, o município ofertou salas de surdos em uma escola para surdos e ouvintes. Nos últimos anos, essas salas foram extintas e a educação municipal de surdos acontece em classes comuns, de acordo com as políticas de inclusão escolar. No período de tempo recortado para a investigação, predominou a educação bilíngue, proposta que foi se consolidando e assumindo distintas configurações. Sperb e Thoma entendem educação bilíngue "[...] como a proposta que visa garantir aos surdos o acesso à língua de sinais como L1 (primeira língua) e a LP como L2, em respeito à condição de diferença linguística e cultural dos Sujeitos surdos" (2012, p. 55).
Neste estudo, a partir de referenciais metodológicos pós-estruturalistas, não há a intencionalidade de julgar a forma como os surdos de Chapecó foram escolarizados ou formular a verdade acerca da escola ideal para esse público, mas, sim, fomentar a reflexão acerca do currículo e da escolarização de surdos com base em distintas concepções teórico-metodológicas.

\section{PROCEDIMENTOS METODOLÓGICOS}

O desenvolvimento de um projeto de pesquisa pressupõe a definição de uma concepção de ciência e dos percursos metodológicos. Concordo com Costa (2006, p. 72), quando afirma que as ferramentas teóricas “[...] são como óculos, lentes que nos permitem enxergar algumas coisas e outras não. Nossas perspectivas de análise não nos ajudam apenas a compreender um problema, elas nos ajudam a compor o problema".

Após a aprovação do projeto no Comitê de Ética em Pesquisa, o primeiro contato foi com a secretaria municipal de educação de Chapecó. $O$ encontro consistiu em apresentar o projeto e buscar informações acerca dos profissionais que exerceram a função de secretários de educação no período delimitado. Obtivemos, também, da secretaria de educação, a autorização para coletar informações em fontes documentais relativas a registros de programas, projetos e ações de formação continuada promovidos para professores atuantes na educação básica.

Entrevistamos os secretários de educação que permaneceram por mais tempo no cargo em cada gestão. Três secretários ${ }^{1}$ constituem nossa amostra de pesquisa. Um roteiro de tópicos orientou os pesquisadores durante o diálogo com os interlocutores. As entrevistas foram gravadas, transcritas, organizadas em agrupamentos temáticos e, posteriormente, examinadas com base na análise do discurso com referenciais foucaultianos. Segundo Foucault (2006, p. 254), "[...] é preciso considerar o discurso como uma série de acontecimentos, como acontecimentos políticos, através dos quais o poder é vinculado e orientado". Discursos são condicionados por práticas, constituem a realidade. Para o autor, é necessário: "[...] não mais tratar os discursos como conjunto de signos (elementos significantes que remetem a conteúdos ou a representações), mas como práticas que formam sistematicamente os objetos de que falam." (Foucault, 2013, pp. 54-55).

Assim, o discurso é tomado como um "conjunto de enunciados (o que pode ser enunciável) que se apoiem na mesma formação discursiva" (Foucault, 2013, p. 131). O enunciado é "uma função que cruza um domínio de estruturas e de unidades possíveis e que faz com que

\footnotetext{
1Optei por generalizar a expressão "secretário" para simplificar a escrita. Contudo, a amostra da pesquisa é constituída por profissionais dos sexos feminino e masculino.
} 
[estas] apareçam, com conteúdos concretos, no tempo e no espaço" (Foucault, 2013, p. 143).

A análise do discurso foi aplicada tanto às materialidades empíricas decorrentes das entrevistas quanto às fontes documentais ${ }^{2}$ analisadas. Além de documentos indicados pelos entrevistados, outros foram juntados, que são de domínio público, de forma que pudessem subsidiar a compreensão das práticas das duas décadas investigadas.

Embora as entrevistas contemplassem aspectos mais amplos em relação ao processo de formação continuada de professores da Educação Básica, o diálogo foi conduzido questionando acerca da educação de surdos no município e a formação docente para atuar com esse público. Da mesma forma, os demais pesquisadores envolvidos com o projeto questionaram aspectos afins aos seus objetos de investigação, de modo que o material nos possibilitou distintos elementos para análise.

\section{RESULTADOS E DISCUSSÕES}

Formação docente e práticas na educação de surdos derivadas de distintas concepções teóricometodológicas

O estudo evidenciou que, em cada tempo histórico, distintas concepções teórico-metodológicas guiaram as práticas docentes na educação de surdos. Nos primeiros anos da década de 1980, eram comuns os exercícios orofaciais, de sopro e sucção (soprar, com um canudinho de refrigerante pedacinhos de papel, provocando seu movimento, espalhando-os ou sugando-os), de movimentação da língua (remover alimentos do palato, a exemplo de pó de gelatina ou de leite em pó); repetição de sons olhando para os lábios dos profissionais e para o espelho; repetição de nomes de figuras, entre outras atividades constituíam o currículo educacional de surdos. O oralismo prevaleceu como filosofia predominante no período de 1880 a 1960, "[...] fazendo com que toda a escolarização dos Surdos, bem como o acesso ao conhecimento (informal ou científico) fosse dependente da possibilidade de oralização, o que, na maioria dos casos, não acontecia (Fernandes, 2012, p. 39). Contudo, na região de Chapecó essa metodologia persistiu até meados da década de 1980.

Tempos depois, ganhava evidência a proposta da Comunicação Total para estudantes surdos, que incluía a oralização e sinalização concomitantemente. Goldfeld (2001, p. 38) salienta que essa filosofia "também se preocupa com a aprendizagem da língua oral pela criança surda, mas acredita que os aspectos cognitivos, emocionais e sociais não devem ser deixados de lado, em prol do aprendizado exclusivo da língua oral".

${ }^{2}$ Lei Complementar $\mathrm{n}$ ㅇ 108 (2000); Resolução COMED no 001 (2011); Secretaria de Educação Chapecó (2013).
Segundo Goldfeld, a comunicação total evidenciou maior eficiência, se comparada ao oralismo, "[...] já que leva em consideração aspectos importantes do desenvolvimento infantil e ressalta o papel fundamental dos pais ouvintes na educação de seus filhos surdos" (Goldfeld, 2001, p. 42). Os sinais adotados na comunicação total representam gestos, mas não caracterizam uma língua, segundo Goldfeld. Nesse sentido, tanto o oralismo quanto a comunicação total não foram consideradas perspectivas exitosas.

Fernandes (2012, p. 35) expressa que, embora a língua de sinais estivesse proibida por longas décadas, "sobreviveu em sala de aula até 1957, continuando a ser utilizada, às escondidas, pelos alunos, nos banheiros, pátios e corredores da escola, longe do olhar vigilante dos cuidadosos mestres", num movimento de resistência surda, que propiciou a consolidação do bilinguismo, cujo objetivo é "levar a criança surda a adquirir proficiência em LIBRAS e Português" (Capovilla, Raphael, \& Mauricio, 2012, p. 73).

A Libras, reconhecida no Brasil pela Lei 10.436, de 24 de abril de 2002, é definida em seu Artigo 1으, parágrafo único, como "[...] a forma de comunicação e expressão, em que o sistema linguístico de natureza visual-motora, com estrutura gramatical própria, constitui um sistema linguístico de transmissão de ideias e fatos, oriundos de comunidades de pessoas surdas do Brasil".

O Decreto n. 5.626/2005, no seu Art. 20, define que "considera-se pessoa surda aquela que, por ter perda auditiva, compreende e interage com o mundo por meio de experiências visuais, manifestando sua cultura principalmente pelo uso da Língua Brasileira de Sinais - Libras".

O município de Chapecó, na época, foi inovador no reconhecimento da Língua de Sinais - Libras, por meio da Lei Complementar no 108 de 23 de outubro de 2000, que "reconhece como meio de comunicação objetiva e de uso corrente a Língua Brasileira de Sinais - Libras e dispõe sobre sua implantação na rede municipal de ensino para surdos e dá outras providências".

Estudos que evidenciam o período anterior a 1996 (Luchese, 2016), indicam que a formação de professores atuantes com estudantes surdos em Chapecó, em cada tempo, seguiu as tendências nacionais. A oferta de educação para surdos no município locus da pesquisa aconteceu, até final da década de 1990, em escolas da rede estadual e a Fundação Catarinense de Educação Especial (FCEE), vinculada à Secretaria Estadual de Educação, foi determinante na formação profissional dos professores atuantes com surdos. Estudos realizados no Instituto Nacional de Educação dos Surdos (INES), no Rio de Janeiro, também foram de grande relevância para a formação dos professores de surdos de Chapecó.

Na década de 2000 a 2010, Chapecó viveu a transição da comunicação total para o bilinguismo. Foram 
criadas salas de educação bilíngue na Escola Básica Municipal São Cristóvão, na qual conviviam estudantes e professores surdos e ouvintes.

A partir de 2005, o município de Chapecó passou a assumir, seguindo a tendência nacional, a inclusão de surdos nas turmas regulares como proposta educacional, como previsto na Política Nacional de Educação Especial na Perspectiva da Educação Inclusiva (MEC, 2008).

Nos últimos anos do período investigado, o município de Chapecó assume a Educação Inclusiva, contemplando a proposta do Atendimento Educacional Especializado (AEE), previsto na Resolução nㅇ 4, de 02 de outubro de 2009, que institui Diretrizes Operacionais para o Atendimento Educacional Especializado na Educação Básica, modalidade de Educação Especial.

Segundo o Projeto Político Pedagógico da Educação Básica da Rede Municipal de Ensino de Chapecó (Secretaria de Educação Chapecó, 2013), ${ }^{3}$ no ano de 2006, foi implantado o Centro de Referência em Educação Especial (CREESP), composto por profissionais da área clínica: Neuropediatria, Fonoaudiologia, Psicologia, Psicopedagogia. O documento registra, também, a instalação progressiva das Salas de Recursos Multifuncionais e intensificação da oferta de cursos de Libras para professores.

O Projeto Político Pedagógico da Educação Básica da Rede Municipal de Ensino de Chapecó ressalta que, em 2010, foi criado o projeto SASE (Serviço de Atenção à Saúde do Escolar), em parceria com a Secretaria de Saúde, com o objetivo de "atender os alunos encaminhados pelo setor de Educação Especial do município que necessitam de avaliação e atendimento especializado, que será feito por uma equipe formada por: Psicólogos, Fonoaudiólogos, Psicopedagogos e Médico". (Secretaria de Educação Chapecó, 2013, p. 63).

A Resolução COMED no 001, de 30 de novembro de 2011, fixa normas para a Educação Especial do Sistema Municipal de Ensino de Chapecó e, no Capítulo II, trata dos recursos e serviços, no que se refere à educação de surdos.

\section{O discurso dos dirigentes educacionais}

Para aprofundar as noções de discurso e de análise do discurso na perspectiva foucaultiana, é importante ressaltar a definição do autor, na compreensão de que analisar as materialidades coletadas nas entrevistas com os gestores educacionais não pressupõe desvelar questões escondidas em seus enunciados. Fischer (2001), amparada em Foucault, salienta que para analisarmos os discursos precisamos recusar as interpretações fá-

${ }^{3}$ O Projeto Político Pedagógico da Educação Básica da Rede Municipal de Ensino de Chapecó possui uma nova versão, atualizada em 2018, que não foi analisada para este texto, por não contemplar o período do estudo desenvolvido. ceis, a busca insistente do sentido último ou do sentido oculto. Afirma que, para Foucault, “[...] há enunciados e relações, que o próprio discurso põe em funcionamento. Analisar o discurso seria dar conta exatamente disso: de relações históricas, de práticas muito concretas, que estão 'vivas' nos discursos”. (Fischer, 2001, pp. 198-199).

Como mencionado no texto, três profissionais que ocuparam o cargo de secretários de educação, no recorte temporal da pesquisa, foram entrevistados. No que se refere à educação de surdos, indagamos acerca da oferta de educação de surdos e formação docente. As narrativas evidenciam as concepções teórico-metodológicas preponderantes em cada período.

O Entrevistado $A$ relata as inquietudes em relação à educação especial e, nesse contexto, à educação de surdos. Destaca a criação de uma escola de surdos como importante empreendimento daquela gestão, com sete classes exclusivas inseridas em uma escola de Educação Básica da rede regular.

A educação especial, acho que ainda hoje não está resolvida. [...] Como é que nós chegamos na escola de surdos? A gente ouviu a comunidade de surdos. Era a APADAC $C^{4}$ tinha uma associação de surdos, acho que eram duas entidades. [...] Eram duas entidades da população surda. E eles vieram com a demanda muito grande de regulamentar a língua de sinais. [...] Então, o direito à Libras, era isso que eles traziam, e direito à educação. $E$ as duas associações defendiam a questão do surdo, inclusive esse conceito de que a primeira língua é a língua de sinais, que português é a segunda. Defendiam o direito à educação de surdos, bilíngue. Então, foi a partir daí que a gente criou. [...] no debate com as entidades $e$ comunidade surda é que chegamos à conclusão de que o caminho era construir a educação de surdos exclusiva. [...] Fizemos a avaliação de que poderia ser interessante construir junto de uma outra escola de ouvintes. [...] Tendo o espaço físico, construímos lá no São Cristóvão. Então tínhamos no mesmo lugar as turmas de educação de surdos, mas o refeitório, o ginásio de esportes, os espaços comuns da escola, para o recreio e tal, eram comuns. Aí tinha os surdos e tinha os ouvintes e os professores bilíngues para trabalhar com as crianças e chamar toda a comunidade surda. Inclusive formaram várias turmas de adultos. [...] pessoas adultas que tinham ido 10, 15 anos na escola [...] e que não eram alfabetizadas. [...] Acho que poucos também sabiam a própria língua de sinais.

\footnotetext{
${ }^{4}$ Fazendo referência à Associação de Pais e Amigos de
} Deficientes Auditivos de Chapecó. 
O Entrevistado $A$ reitera a sua convicção de que pessoas surdas precisam ter acesso a escolas ou turmas exclusivas para surdos, pelo menos na educação infantil e ensino fundamental. Salienta a forma como a proposta foi construída, com a participação da comunidade surda, dos professores que militavam na educação de surdos, professores e pesquisadores de universidades, e não como uma imposição municipal.

Com relação à formação de professores no período, esse afirma que, a partir da própria construção da proposta da educação de surdos, buscaram o conhecimento que as entidades de surdos possuíam, bem como dos professores das universidades. Houve o envolvimento dos professores da rede que estudavam essa área, e foram ofertados seminários, leituras e cursos. Depois que as turmas foram organizadas e começaram a funcionar, a experiência gerou novas demandas, inclusive, com a criação de grupos de estudos e formação continuada, valorizando as vivências práticas.

Na sequência, o Entrevistado $B$ explicita ações desenvolvidas durante sua gestão:

Eu acho que nós avançamos na educação especial. Principalmente, na educação de surdos. Nós avançamos muito. Nós criamos uma escola. Nós criamos a legislação. É, obrigatoriedade da língua de sinais. [...] A educação especial é muito ampla, muito complexa. Eu acho que o que mais nós deixamos a desejar foi na inclusão na escola na rede regular. Essa dificuldade a gente teve. Não é que teve a dificuldade, é que nós priorizamos conforme era possível. Mas, avançamos muito na relação com os surdos tanto é que se formaram muitos alunos. A gente começou a trazer o debate de (sic) Libras para dentro da rede regular. [...] Mas, eu diria que na educação especial ainda a gente fez pouco diante do grande desafio que tinha.

Com relação à formação de professores, afirma o entrevistado que implementaram o debate da Libras na da rede regular, conhecimento que ainda era marginalizado. Afirma que os professores de surdos participavam da formação geral de professores, mas continuavam inseridos na estratégia de estudos destacada pelo entrevistado anterior, e também na atuação como formadores dos professores da rede que não atuavam com surdos.

O Entrevistado $C$ evidencia a política de inclusão, opção que ganhou força no país e é incorporada também no contexto da pesquisa. Afirma:

Inclusão. Inclusão. Inclusão. Mas, foi aí que nós começamos a entender, que não adianta. Daí que nós começamos a escrever o curso de Libras que não tinha em Chapecó. Nós tínhamos três, quatro profissionais ministrando aula, há seis, sete anos atrás. E aí nós começamos a criar o curso de Libras dentro da Secretaria de Educação. Eles faziam o curso à noite, a gente fazia na secretaria. [...] Hoje, nós temos um CEIM ${ }^{5}$ que tem um professor que dá aula de Libras para as crianças. É uma maravilha aquilo. Ver os pequeninhos. Então, agora temos professores de Libras em todas e acho que evoluiu muito essa questão.

Salienta, ainda, o Entrevistado $C$, a criação e funcionamento do Serviço de Atenção à Saúde do Escolar (SASE).

[...] Começamos a perceber que a inclusão realmente não acontecia na escola. A inclusão era inclusão no papel, sempre digo, a inclusão entre aspas. Então, nas escolas, nós não tínhamos sala de recursos, por exemplo. Hoje, tem em todas as escolas, em todos os centros de educação infantil. [...] Temos professores habilitados. Deve ter mais de 700 crianças, não sei o número, mas (sic) crianças com deficiência que são atendidas no turno e no contraturno, justamente com pessoas capacitadas, habilitadas. Acho que ali foi dada uma abertura também para os nossos profissionais se capacitarem e entenderem a realidade. E essas crianças sendo realmente bem atendidas. O que que nós tínhamos no início? Nós tínhamos a professora titular e geralmente era um estagiário que atendia a criança junto. [...] Por que que nós criamos o SASE? Porque nós precisávamos de um espaço onde essa criança fosse atendida individualmente fora da escola, com profissionais da área da saúde. Por quê? Porque quando nós encaminhávamos as crianças para a saúde, nós percebíamos que lá também não tinha aquele atendimento que ele deveria ter, específico naquelas condições dele. [...] Então, quando nós criamos o SASE e o pai, o maior problema das pessoas, dessas pessoas que têm necessidades especiais, deficiência, os pais às vezes renegam a criança. Eles também têm problemas. [...] Então, eu sempre digo: uma pessoa deficiente, nós não temos 700 alunos com problemas no SASE, nós temos quatro vezes isso. [...]. Eles não admitem e não querem ser ajudados muitas vezes e assim por diante. Então, às vezes, você tem de tratar a mãe também, ou o pai. E, às vezes, eles não tomam remédio, não dão o remédio para a criança.

Debates e dúvidas sobre o melhor lugar para a escolarização de surdos ainda permanecem: em escolas/ classes especiais ou incluídos em turmas regulares?

${ }^{5}$ Fazendo referência a um Centro de Educação Infantil. 
Alguns autores, a exemplo de Thoma (2006, p. 22), apontam fragilidades nas experiências de inclusão de estudantes surdos em classes regulares, de maioria ouvinte, "associadas a um amplo leque de questões que não foram devidamente previstas e planejadas pelas escolas, pelos docentes e pela gestão". A autora alerta que a inclusão não tem produzido os resultados almejados. "Talvez não se tenha reconhecido o complexo conjunto de relações, discursos e representações sobre aqueles a serem incluídos que constituem as propostas educacionais e que nos constituem na relação com os estranhos e anormais." (Thoma, 2006, p. 22).

Tensionar a inclusão não significa defender tempos em que a segregação era naturalizada, mas evidenciar a complexidade do processo. "Tensionar a inclusão é refletir acerca de processos que nos subjetivam e governam, que nos fazem assumir como verdades pressupostos que nos causaram, ou causarão estranhamento em algum tempo." (Pieczkowski, 2014, p. 189).

Distintos estudos evidenciam a importância da convivência entre surdos para a aprendizagem da língua de sinais, uma vez que a maioria dos surdos nasce em famílias ouvintes. O fato de os surdos conviverem entre si não significa necessariamente homogeneização, uma vez que cada surdo é único, diferente. Esse pode ser um argumento para afirmar que uma classe ou escola de surdos não representa, necessariamente, um espaço segregado, uma vez que a diversidade está presente nesse contexto.

Pessoas surdas apresentam diferentes manifestações acerca do espaço desejado de escolarização: escolas especiais, classes exclusivas de surdos em escolas regulares, ou classes comuns, nas quais convivem surdos e ouvintes. Para Lopes e Veiga-Neto (2006, p. 93), "Escola e comunidade surda parecem ser conceitos e espaços que se confundem no imaginário surdo. Muitos são os depoimentos surdos que, ao falarem de sua preferência pela escola de surdos, enunciam a possibilidade do encontro e do movimento político [...]". No dizer dos autores "Embora a escola de surdos continue sendo um dos lugares onde a aproximação surda acontece sem gerar grandes resistências sociais e familiares, ela continua possuindo uma tarefa diferente daquela que poderíamos atribuir a uma associação de surdos organizada" (p. 97). Lopes e Veiga-Neto (2006) salientam a pesquisa com depoimentos de adolescentes surdas que declaram que a escola de surdos é melhor para a interação e a convivência surda, mas que como espaço de ensino e de aprendizagem é deficitária.

Cerejo (2017), em sua dissertação de Mestrado em Educação, denominada "Queixas escolares: um estudo sobre o encaminhamento de crianças ao Serviço de Atenção à Saúde do Escolar (SASE)", tendo como locus de estudo o município de Chapecó, afirma que, ao ana- lisar o processo de funcionamento do serviço, percebeu a fragilidade de diálogo entre os profissionais da escola e do SASE, tanto na elaboração do diagnóstico, quanto no processo de atendimento. Salienta que "[...] ambas as instituições parecem partilhar a compreensão de que o problema ocorre no estudante, individualmente, sendo que ele é portador de um desajuste que precisa ser tratado". (Cerejo, 2017, p. 84). O autor conclui seu estudo salientando que "[...] na atual situação o modelo de atendimento que se efetiva no SASE reproduz o padrão tradicional de atendimento clínico da criança, entendida como um ser em desajuste e que precisa ser adaptado." (Cerejo, 2017, p. 85).

Em relação à educação de surdos, a cultura ouvintista predominou, historicamente, dentro do modelo clínico e demonstra as táticas de caráter reparador e corretivo da surdez, considerada defeito e passível de normalização. Wrigley alerta para a lógica ouvintista, de que surdos são pessoas com ouvidos defeituosos. "Os negros são pessoas brancas que possuem pele escura. Se pudéssemos consertar a pele, eles seriam brancos. As mulheres são homens com genitália errada...; e por aí vai." (Wrigley, 1996, citado por Ströbel, 2007, p. 24).

Para compreender os discursos e como são produzidos os efeitos de verdade, amparei-me em Foucault, na sua compreensão de que os discursos não são em si nem verdadeiros nem falsos. Foucault busca trabalhar a verdade no tempo e isso atribui originalidade à sua obra. Nesse sentido, Lockmann (2013, p. 60), afirma que, para cada época e cada sociedade,

[...] podem ser identificados traços específicos de racionalidade particular, orientada e conduzida por determinados princípios considerados verdadeiros naquele período. Essa racionalidade não é apenas produzida por esses princípios verdadeiros, mas também os produz e se manifesta mediante regimes de verdade específicos que vão, ao mesmo tempo, conduzir as condutas dos sujeitos e se atualizarem por meio dessas práticas de condução. Trata-se então, de uma relação sempre imanente, a partir da qual a racionalidade é, ao mesmo tempo, produto e produtora de regimes de verdade.

Nesse sentido, Revel (2005), amparada em Foucault, destaca que as verdades são produzidas ao longo da história e estão conectadas às relações de poder, são regimes de verdades firmados por determinada sociedade e época. Machado (2011, p. XI) evidencia que para Foucault, toda teoria é temporária "[...] acidental, dependente de um estado de desenvolvimento da pesquisa, que aceita seus limites, seu inacabado, sua parcialidade, formulando os conceitos que esclarecem os dados [...]". Isto é, as verdades são produzidas de acordo com 
[...] os tipos de discurso que elas acolhem e fazem funcionar como verdadeiros; os mecanismos e as instâncias que permitem distinguir os enunciados verdadeiros ou falsos, a maneira como uns e outros são sancionados; as técnicas e os procedimentos que são valorizados para a obtenção da verdade; o estatuto daqueles que têm o poder de dizer aquilo que funciona como verdadeiro. (Revel, 2005, p. 86).

Assim, estruturas de poder e distintos aportes teóricos definem diferentes concepções de surdez, de formação profissional para atuação com estudantes surdos e diferentes propostas de escolarização desse público. O contexto investigado passou pela oralização, pela comunicação total e mais recentemente, contempla a educação bilíngue. Passou, também, pela segregação e pela inclusão de estudantes surdos nas turmas das escolas regulares, proposta adotada na atualidade. Contudo, o Decreto no 10.502, de 30 de setembro de 2020, que institui a Política Nacional de Educação Especial: Equitativa, Inclusiva e com Aprendizado ao Longo da Vida, sinaliza, no Art. 20, incisos VIII e IX, para a possibilidade de escolas bilíngues de surdos e classes bilíngues de surdos. O Decreto tem gerado muitas reações e críticas de instituições, famílias, pessoas com deficiência, pesquisadores e profissionais. Devido à recente publicação e os seus desdobramentos ainda incertos, o conteúdo do Decreto não será aprofundado neste artigo.

Vale salientar que cada perspectiva teórica e metodológica relativa à educação de pessoas surdas revela a sua complexidade. Tensionar a inclusão não significa refutar, negar ou ser contra, mas refletir acerca dessa opção como algo natural, inquestionável, autojustificado e compreendê-la como um imperativo contemporâneo, estabelecida na complexidade de uma sociedade neoliberal.

\section{CONSIDERAÇÕES FINAIS}

O estudo evidenciou que a Política Municipal de Educação de Surdos de Chapecó, no período investigado, já priorizou a escolarização dos surdos em classes especiais, inseridas em uma escola regular, na qual surdos e ouvintes conviviam, interagiam, aprendiam a Língua Brasileira de Sinais (Libras), os conteúdos escolares ensinados por professores bilíngues, além de vivenciar coletivamente a cultura surda. Também fica evidente, nos depoimentos, o investimento em compreender e acolher as demandas da comunidade surda.

Nos últimos anos do período investigado, gradativamente, a educação de surdos passa a acontecer nas escolas regulares, extinguindo-se as classes exclusivas de surdos, acolhendo-se a Política Nacional de Educação Especial. O movimento se dá na direção da disponibi- lização de intérpretes e instrutores de Libras e professores bilíngues nas classes comuns e no Atendimento Educacional Especializado (AEE) em Salas de Recursos Multifuncionais, o que também passa a ser consolidado. Ouvintes e surdos acessam com crescente intensidade à Libras. O município investe também no Serviço de Atenção à Saúde do Escolar (SASE), como um suporte escolar às políticas de educação especial e inclusão.

Nas narrativas dos entrevistados são identificadas distintas representações operando nos enunciados: discursos pedagógicos, clínicos-patológicos, psicológicos, dentre outros. Os discursos pedagógicos indicam adaptações curriculares, oferta de serviços e de profissionais, assim como mudança nas estratégias escolares. Os discursos clínico-patológicos buscam identificar o diagnóstico do estudante e as suas ausências em relação aos considerados "normais", como se fosse necessário desencadear movimentos pedagógicos de normalização e de correção. Por sua vez, os discursos psicológicos generalizam e justificam atitudes ou comportamentos dos sujeitos com deficiência, assim como de suas famílias. Às vezes, tais discursos se mesclam, se misturam.

O estudo instiga a novas investigações, a exemplo de compreender a trajetória dos estudantes surdos que frequentaram classes exclusivas para surdos em escolas regulares. Acessar em Libras e conviver com outros surdos na infância representa um diferencial para a aprendizagem e o desenvolvimento? Esse seria um estudo longitudinal, ancorado na clareza de que muitos são os fatores que influenciam a aprendizagem e o desenvolvimento de qualquer estudante, portanto, de difícil conclusão. Contudo, muitas pesquisas apontam para a importância de a criança ter contato com a cultura surda e a Língua de Sinais o mais precocemente possível, considerando que a maioria dos surdos nasce em famílias ouvintes e, portanto, vivem a condição de estrangeiros no próprio país, na própria família e nos demais espaços sociais.

Concordo com Veiga-Neto e Lopes, quando alertam que é preciso ser prudente frente às práticas inclusivas, não assumindo precipitadamente juízo de valor sobre estas e que da maneira como as políticas de inclusão vêm sendo formuladas e executadas no Brasil "[...] parecem ignorar a própria diferença. Assim, ao invés de promoverem uma educação para todos, elas correm o risco de realizar uma inclusão excludente das diferenças" (Veiga-Neto \& Lopes, 2007, p. 947).

Tenho conviç̧ão dos ganhos possibilitados pela presença de crianças com distintas formas de deficiência/ diferença nas redes regulares de ensino, pois a separação, a segregação, limitou a vida e a aprendizagem de quem teve negado o direito de acesso, de aprendizagem, de convivência social na escola, lugar da diversidade, por excelência. No entanto, questiono se a convivência 
escolar de surdos em salas exclusivas, nos primeiros anos de educação/escolarização, o que favorece a apropriação a língua de sinais, não seria uma forma de inclusão. Reconheço avanços imensos na apropriação e reconhecimento da língua de sinais e nas experiências exitosas de inclusão. Ou seja, há distintas maneiras de construirmos esse caminho, pautado, especialmente, no reconhecimento da diferença, no direito de ser diferente e ser entendido nas próprias reivindicações.

Para finalizar, considero necessária a prudência nos olhares e práticas clínicas, para que não haja um retrocesso na concepção da surdez, do sujeito surdo ou sujeitos que apresentam deficiência.

Foucault, em seus escritos, nos ensina a desnaturalizar o que está posto, o que pensamos e fazemos, e a criar novas alternativas para a ação. Assim, nos ajuda a compreender a complexidade do processo de inclusão e a tensionar a escola que classifica, normatiza e busca normalizar toda a diferença.

\section{REFERÊNCIAS}

Lei n. 10.436, de 24 de abril de 2002. Dispõe sobre a Língua Brasileira de Sinais - Libras e dá outras providências. Diário Oficial [da] República Federativa do Brasil, Brasília, DF.

Decreto n. 5.626, de 22 de dezembro de 2005. Regulamenta a Lei no 10.436 , de 24 de abril de 2002, que dispõe sobre a Língua Brasileira de Sinais - LIBRAS, e o art. 18 da Lei no 10.098, de 19 de dezembro de 2000. Diário Oficial [da] República Federativa do Brasil, Brasília, DF.

Ministério da Educação [MEC] (2008). Política Nacional de Educação Especial na Perspectiva da Educação Inclusiva. MEC: Secretaria de Educação Especial.

Decreto no 10.502, de 30 de setembro de 2020. Institui a Política Nacional de Educação Especial: Equitativa, Inclusiva e com Aprendizado ao Longo da Vida. Diário Oficial [da] República Federativa do Brasil, Brasília, DF.

Capovilla, F. C.; Raphael, W. D.; Mauricio, A. C. L. (2012). Novo Deit-Libras: dicionário enciclopédico ilustrado trilíngue: língua brasileira de sinais. São Paulo: Universidade de São Paulo.

Cerejo, J. (2017). Queixas escolares: um estudo sobre o encaminhamento de crianças ao Serviço de Atenção à Saúde do Escolar (SASE). (Dissertação de Mestrado). Universidade Comunitária da Região de Chapecó - Unochapecó, Chapecó (SC). Recuperado de: http://konrad.unochapeco.edu. br:8080/pergamumweb/vinculos/0000f6/0000f68d.pdf

Lei Complementar no 108, de 23 de outubro de 2000. Reconhece como meio de comunicação objetiva e de uso corrente a Língua Brasileira de Sinais - Libras e dispõe sobre sua implantação na rede municipal de ensino para surdos e dá outras providências. Câmara Municipal do Chapecó, Chapecó, SC.

Resolução COMED no 001 de 30 de novembro de 2011. Fixa normas para a Educação Especial do Sistema Municipal de Ensino de Chapecó. Conselho Municipal de Educação COMED, Chapecó, SC.

Secretaria de Educação Chapecó. (2013). Projeto Político Pedagógico da Educação Básica da Rede Municipal de Ensino de Chapecó. Chapecó, SC.

Costa, M. V. (2006). O magistério e a política cultural de representação e identidade. In: Costa, M. V. (Ed.), O magistério na política cultural (pp. 69-92). Canoas: ULBRA.

Fernandes, S. (2012). Educação de Surdos. Curitiba: Intersaberes.

Fischer, R. M. B. (2001). Foucault e a análise do discurso em educação. Cadernos de pesquisa, 114(1), 197-223. DOI:10.1590/S0100-15742001000300009

Foucault, M. (2006). Diálogo sobre o poder. In: Ditos \& Escritos IV: Estratégia, poder-saber (2ª ed, Vera Lucia Avellar Ribeiro Trad., pp. 253-266). Rio de Janeiro: Forense Universitária. Trabalho original publicado em 1994.

Foucault, M. (2013). A arqueologia do saber (8ª ed., Luiz Felipe Baeta Neves Trad). Rio de Janeiro: Forense Universitária. Trabalho original publicado em 1969.

Machado, R. Introdução: por uma genealogia do poder. In: Foucault, M. Microfísica do poder. (29 ed. Roberto Machado Trad). Rio de Janeiro: Graal, 2011. pp. VII-XXIII. Trabalho original publicado em 1979.

Goldfeld, M. (2001). A criança surda: linguagem e cognição numa perspectiva sócio-interacionista. São Paulo: Plexus.

Lockmann, K. (2013). A proliferação das políticas de assistência social na inclusão escolarizada: estratégias de governamentalidade neoliberal. (Tese de doutorado). Universidade Federal do Rio Grande do Sul (RS). Recuperado de https://lume.ufrgs.br/handle/10183/79669

Lopes, M. C.; Veiga-Neto, A. (2006). Marcadores culturais surdos: quando eles se constituem no espaço escolar. Perspectiva, 24(3), n. Especial, 81-100.

Lopes, M.C. (2011). Surdez \& educação (2 a ed.). Belo Horizonte: Autêntica.

Luchese, A. (2016). Formação docente para a atuação com estudantes surdos (Dissertação de Mestrado). Universidade Comunitária da Região de Chapecó - Unochapecó, Chapecó (SC).

Pieczkowski, T. M. Z. (2014). Inclusão de estudantes com deficiência na educação superior: efeitos na docência universitária. (Tese de Doutorado). Universidade Federal de Santa Maria, Santa Maria (RS). Recuperado de https:// repositorio.ufsm. br/handle/1/3480

Revel, J. (2005). Michel Foucault: conceitos essenciais (M. R. Gregolin; N. Milanez; C. Piovesani, Trad.). São Carlos: Clara Luz.

Sperb, C. C.; Thoma, A. S. (2012) Atendimento Educacional Especializado (AEE) e Educação de surdos. Textura. Canoas, 14(25), 52-66.

Thoma, A.S. (2006). Educação dos surdos: dos espaços e 
tempos de reclusão aos espaços e tempos inclusivos. In: Thoma, A. S.; Lopes, M. C. (Ed.), A Invenção da surdez II: espaços e tempos de aprendizagem na educação de surdos (pp. 9- 25). Santa Cruz do Sul: EDUNISC.
Veiga-Neto, A.; Lopes, M. C. (2007). Inclusão e governamentalidade. Revista Educação e Sociedade, 28(100), 947-963.

Pesquisa financiada com recursos de Chamada Pública FAPESC /2015 - apoio a grupos de pesquisa das instituições do sistema ACAFE (Associação Catarinense das Fundações Educacionais).

Recebido: 01 de junho de 2019

Aprovado: 10 de outubro de 2020 